\title{
Growing practices and the use of potentially harmful chemical additives among a sample of small-scale cannabis growers in three countries
}

\author{
Simon LENTON ${ }^{1}$ \\ Vibeke A. FRANK ${ }^{2}$ \\ Monica J. BARRATT ${ }^{3,1,4}$ \\ Gary R. POTTER ${ }^{5}$ \\ Tom DECORTE ${ }^{6}$
}

1. National Drug Research Institute, Curtin University, Australia

2. Centre for Alcohol and Drug Research, Aarhus University, Denmark

3. Drug Policy Modelling Program, National Drug and Alcohol Research Centre, UNSW Australia.

4. Behaviours and Health Risks Program, Burnet Institute, Australia

5. Lancaster University Law School, UK

6. Institute for Social Drug Research (ISD), Ghent University, Belgium

Contact details for Corresponding Author:

Phone: +61 892661603

Fax: +61 892661611

Email: s.lenton@curtin.edu.au 


\section{Abstract}

Background: With the growth of legal cannabis markets there has been recognition of the adverse impacts of certain cannabis growing practices, notably, use of harmful chemicals. A major concern has been use of Plant Growth Regulators (PGRs) which limit plant size and stimulate bud production. These chemicals, many of which have been banned from food crops, have been found unlisted in cannabis growing nutrients sold online or in hydroponic stores. This study describes the cannabis growing practices used by small-scale recreational cannabis growers and specifically their self-reported use of chemicals.

Methods: Web survey data from 1,722 current and recent cannabis growers in Australia, Denmark and the UK, who were asked about their cannabis growing practices, including the use of fertilizers and supplements.

Results: Overall $44 \%$ of the sample reported using any chemical fertilizers, supplements or insecticides. Logistic regression indicated that the only unique predictor of the use of chemicals was growing hydroponically.

Conclusion: Problems associated with product labelling and uncertainty regarding product constituents made it difficult for growers and the researchers to determine which products likely contained PGRs or other harmful chemicals. There is a need for further research to analyze constituents of chemical products marketed to cannabis growers.

(Abstract 199 words)

Key words: Cannabis, marijuana, policy, cultivation, on-line survey, international comparative research.

(Full Paper 4129 words) 


\subsection{Introduction}

With the growth of legal medical and recreational cannabis markets in the USA, Canada, Israel, and elsewhere there has been increasing recognition of the adverse impacts of certain cannabis growing practices. In North America in particular, the use of potentially harmful and sometimes carcinogenic chemical pesticides, fertilizers, 'nutrients' and bud-stimulators has posed challenges for the development and implementation of regulations and procedures of quality assurance systems and product testing in legal seed-to-sale cannabis cultivation and production systems (Subritzky et al., 2017). Advocates within the cannabis community have been instrumental in raising concerns about the use of these chemicals and bringing them to the attention of regulators in jurisdictions which have legal medical and recreational cannabis markets (e.g. Integral Hydroponics, 2015; Manic Botanix, undated; Sirius, 2016).

Over recent years, the identification of the use of Plant Growth Regulators (PGRs), which limit the size of the plant and stimulate female flower (bud) production, has been of major concern (Sirius, 2016). These chemicals, many of which have been banned from food crops over recent decades as they were identified as carcinogens, have been appearing in legal and illegal cannabis crops (Subritzky et al., 2017). Although the impact of PGRs when combusted and inhaled is largely unknown, one study determined that up to $69.5 \%$ of the chemical residues (including the PGR paclobutrazol) on plant material were transferred to mainstream smoke and concluded that the potential of chemical contamination being transferred to cannabis users was substantial (Sullivan et al., 2013). A study of concentrates sold in the California medical marijuana market between December 2012 and February 2013 found 22.8\% contained paclobutrazol (Raber et al., 2015). Two PGRs, paclobutrazol and daminozide, were found to be present but unlisted in several fertilizers and supplements that have been sold for years in hydroponic stores and other retail outlets targeting cannabis growers (Hermes, 2011). The public health outcomes of the use of these chemicals is not definitively known as the 
toxicological studies have been carried out with animal models such as rats and zebra fish (e.g. Robens, 1980) yet, the toxicological evidence has been enough to have them banned in food crops. Another 'naturally occurring' PGR, triacontanol, has been reported in newer products and the toxicity, or otherwise, of this chemical has been debated on cannabis grower internet forums. Furthermore, it has not been demonstrated that these newer products do not contain other toxic PGRs, because there are no legal requirements for testing and labelling these products. The recent contamination of legal medicinal cannabis crops in Canada (Robertson, 2017) and Colorado (Miller and Looi, 2017) with a pesticide, myclobutanil, which has been found to produce cyanide on combustion, has added to the list of chemical contaminants of concern in harvested cannabis.

In the Netherlands, where cannabis is sold through 'coffee shops' but cannabis production is illegal (with an exception of home cultivation of 5 plants), a study of cannabis samples from different 'cannabis coffee shops' found that 23 of 25 contained pesticides, 11 of which exceeded the amount approved for herbal medicines (Venhuis and van de Nobelen, 2015).

Cannabis growing can range from simple to complicated depending on the growing practices employed. Media representations of cannabis cultivation often associate 'professional' types of growing incorporating artificial lighting, technical equipment (timers, air filters ventilators, carbon filters, etc.) and the use of pesticides and bud stimulators with large scale (criminal) growers, but these representations may be misleading (Decorte, 2010). Many small-scale, noncommercial growers are informed by the internet, peers, specialized magazines and grow shops, and may also use sophisticated techniques and equipment (Decorte, 2010; Potter 2010). Whether or not this 'professionalism' among small-scale growers entails the use of pesticides and bud-stimulators (and the PGRs they might contain), remains largely unknown. 
A quick internet search can reveal copious webpages which discuss locations for growing (outdoor and indoor options), grow medium (soil and non-soil), lighting (sunlight and artificial light) and other equipment and techniques. Growing practices also cover different garden styles, including various forms of hydroponic cultivation techniques (e.g. ebb and flow watering, deep water culture, aeroponics) (See Howtogrowmarijuana.com, undated), and methods of plant training (topping, training, pruning, etc.) which are used to maximize the exposure to light and produce the highest yield of flowering heads (see Kodiak, 2009). A related issue is the practice of 'flushing' cannabis plants. This practice involves growers ceasing supply of nutrients to their plants and simply using water up to two weeks before harvest, with the belief that the plant will consume any traces of nutrients in its tissues and so produce a 'smoother product' uncontaminated by chemicals added in the preceding growing phase (Haze, 2016; Potter, 2010). While some growers believe that this practice will rid the plant of added chemicals including PGRs, there is much uncertainty and debate regarding flushing in the online cannabis grower community (see for example Gore, 2012; N3ro, 2017). Moreover, we understand that whilst flushing may be used to correct a nutrient imbalance, or remove accumulated salts, because most PGRs are systemic, flushing does not actually remove them from the plant (Steven Carruthers, personal communication 29.04.17).

In this contribution we describe the growing practices used by primarily small-scale cannabis growers and, specifically, their self-reported use of chemicals and predictors of this use. In 2012-2013 our Global Cannabis Cultivation Research Consortium (GCCRC) conducted an online survey of largely small-scale cannabis cultivators in 11 countries (Barratt, Potter et al., 2015; Decorte and Potter, 2015; Hakkarainen et al., 2015; Lenton et al., 2015; Potter et al., 2015). This paper presents data from a three-country subsample who were asked questions regarding (i) their cannabis growing practices and (ii) specifically their use of chemical 
fertilizers, nutrients, bud stimulators, insecticides and other products, and attempted to identify those which have been shown to contain highly toxic Plant Growth Regulators (PGRs).

To our knowledge this is the first study to systematically investigate the use of chemicals by cannabis growers. This issue has clear policy implications regarding regulation in both the legal cannabis market and the market for fertilizers and nutrients sold to people who illegally grow cannabis. It also has relevance clinically as the risk of cannabis contamination by harmful chemicals may be salient to cannabis users who are dependent or experiencing other cannabisrelated harms regarding decisions about continuing, reducing or ceasing use. This is particularly relevant in the context of motivational interviewing; (Diclemente et al., 2017).

\subsection{Method}

This paper utilizes data from a subsample of an anonymous web survey of largely 'small-scale' cannabis cultivators, $18 \mathrm{yrs}$ and over. The rationale, scope, content, design and limitations of the study have been described elsewhere (Barratt et al., 2012; Barratt and Lenton, 2015; Barratt, Potter et al., 2015). All respondents across the eleven countries that ran the GCCRC survey were asked a core set of 35 questions titled the International Cannabis Cultivation Questionnaire (ICCQ) (Decorte et al., 2012). Additionally, respondents in the subsample from Australia, Denmark and the UK, used in this paper, were asked additional questions about their growing practices and use of fertilizers, supplements and insecticides. Specifically, these respondents were asked: What kind of medium are the plants' roots suspended in? What fertilizers, supplements (e.g. growth agents, bud stimulators) or insecticides do you typically use? Subsequently they were asked to specify the names of the products they typically use.

Although our intention was to identify those products from the open text field which were known to contain PGRs, this approach proved problematic. While there were some brands mentioned which had previously been shown to contain banned PGRs (Sirius, 2016), concerns 
regarding incomplete and sometimes misleading labelling on other products significantly constrained our ability to determine which other products contained PGRs and which did not. We attempted to verify the concerns about chemicals found in products targeting cannabis growers by looking at the online organic certification systems in various countries, yet we were unable to identify any of the chemical fertilizers and additives listed by our respondents as 'organic' fertilizers, nutrients and pesticides. This could mean that they are either not actually organic, or simply that they have not been verified, which leaves us without definitive determination of the status of these products with regards to PGRs. We subsequently consulted an expert from the horticultural hydroponics industry (Steven Carruthers, personal communication 23.03.17) who is the editor of Practical Hydroponics \& Greenhouses, the largest hydroponics magazine in Australia, with a world-wide circulation, and Arno Hazekamp, a toxicologist from the Netherlands who has published on cannabis contamination (Hazekamp, 2005, 2006). Carruthers expressed the opinion that identifying PGRs via brand names was an impossible task and this view was supported by Hazekamp (Arno Hazekamp, personal communication, 22 May 2017). In Carruthers view, many of the nutrients and bud stimulators targeting cannabis growers contained PGRs, even if they were said to be 'certified organic'. He also believed that there was no guarantee that the newer nutrients said to contain triacontanol did not also contain other banned PGRs. For that reason, our analysis was limited to self-report of any use of chemical fertilizers supplements or insecticides. During the data cleaning stage, several cases were identified and corrected where respondents said they only used 'natural or organic fertilizers' yet in their description of the products they used, they mentioned brands which were clearly chemical fertilizers, some of which were known to contain banned PGRs. These were recoded as chemical fertilizers and supplements. A list of fertilizer brands mentioned by respondents by frequency is presented in Appendix 1. 
Respondents were eligible for the study if they: were at least $18 \mathrm{yrs}$ of age; had last grown cannabis not more than 5yrs ago; and completed at least $50 \%$ of 22 core questions in the ICCQ. Overall, 2,595 potentially eligible respondents from the three countries who were asked about their growing practices (Australia, Denmark and the UK) commenced the questionnaire and after the exclusions described above 1,722 cases were eligible for final analysis. Details on the final sample and reasons for exclusion by country are provided elsewhere (Lenton et al., 2015).

\subsection{Analysis}

As we have described elsewhere (Barratt et al., 2012), IP addresses were not collected because familiarity with the target group and piloting emphasized the importance of anonymity. A duplicate cases analysis indicated only $0.4 \%$ of cases were duplicates which was unlikely to affect the results (Lenton et al., 2015). For univariate analyses (chi square for categorical variables and ANOVA and t-test for continuous variables) a conservative alpha level of 0.01 was applied to account for the possibility of type 1 error due to the multiple comparisons.

Univariate predictors of the use of chemical fertilizers, supplements and insecticides were subsequently subjected to logistic regression to explore their unique relationship with the use of chemicals where inter-correlation was accounted for. The logistic regression employed was a backward stepwise model. An alpha level of 0.05 was employed for variables entering the model and variables were retained in the final model if the effect of the variable was significant at an alpha level of 0.10 . An alpha level of 0.05 was also used to determine the significance of predictors in the final model. As list-wise deletion of missing cases in the sample would have reduced the cases available for logistic regression sample to $n=1,051$, multiple imputation as described by Greenland \& Finkle (1995) was used to address missing data which produced a sample of 1,190 cases for logistic regression analysis. 
Decisions as to what variables were included in the logistic regression were based on an exploration of univariate relationships between the predictor and criterion variables and what was known from other analyses including our own work (Lenton et al, 2015). Most variables in the logistic regression were categorical, rather than continuous, but for ease of interpretation, where it made conceptual sense, both continuous and categorical variables with more than two values were dichotomised. Decisions about at which values the variables should be dichotomised were based on an inspection of the distribution of values on the raw or undichotomised variables, along with what made sense from a conceptual point of view (e.g. any employment (FT, PT, casual) vs none). The variables entered into the logistic regression equations were: country of residence of participants; age; gender; employment status; whether they grew cannabis to sell it; the typical area devoted to cannabis growing (dichotomized); the number of mature plants they typically grew; the typical size of their crop in grams; how many crops of cannabis they had grown so far; how many people they grew their crop with; how many people knew about their crop; whether they communicated with other growers online that they had not met face-to-face; and their grow method (soil under natural sunlight (S-NL); soil under artificial light (S-AL); and non-soil under artificial light (NS-AL).

The goodness of fit of the model was sound. The Nagelkerke $\mathrm{R}^{2}$ value indicated that the model accounted for $24.0 \%$ of the total variance and the predictive accuracy of the model was $70.2 \%$ with a sensitivity of $47.8 \%$ and a specificity of $84.8 \%$. The model accurately predicted the observed probabilities (Hosmer and Lemeshow Chi Square Test $=6.221, \mathrm{df}=8, \mathrm{p}=.622$ )

\subsection{Results}

The descriptive statistics in this paper provide an overview of the growing practices of the sample by country and country-specific characteristics. As the data are drawn from a selfselected purposive sample, it is not possible to draw conclusions to the broader population of 
cannabis cultivators. Rather, in this paper, we explore relationships between members of the resultant sample and the analyses should be interpreted in this way (see Barratt, Ferris et al., 2015).

\subsection{The sample}

Table 1 presents by country the demographic characteristics and main growing practices of the whole sample and of those cases included in the logistic regression after data imputation.

\subsection{Grow method and location}

In this study we defined grow method as a combination of the grow medium (soil (S) or nonsoil (NS)) and light source (natural sunlight (NL) or artificial light (AL)). The results by country are presented in Table 2 below and this difference was significant (Chi Square $=191.110, \mathrm{df}=4, \mathrm{p}=.000$ ). Unsurprisingly because of its overall good sunshine, conducive climate and wide-open spaces, S-NL growing was more common in Australia than in Denmark and the UK, but S-AL growing was more common in Denmark and the UK. Growing hydroponically (NS-AL) was reported by a higher proportion of respondents in the UK and Australia.

There were significant differences between countries across most growing locations: most of these seemed associated with climate and issues of space and population density in the three countries. For example, overall, growing in a garden was the most common growing location identified by respondents in Australia (51.5\%) and Denmark (49.4\%), while among UK respondents growing in a cupboard (36.1\%) was the most common location. Locations which were not significantly different between countries were those that are typically associated with more organized, larger scale operations such as growing in a grow room, warehouse or grow house. 


\subsection{Equipment - lighting, other equipment and fertilizer use}

The data on lighting and other equipment used by the growers in this sample are presented in Table 3. The main differences in lighting used between the countries were affected by the larger amount of outdoor growing under sunlight in Australia and Denmark, compared to the UK, and by the higher rate of hydroponic growing in the UK. Similar differences were also reflected in the other equipment used yet it was interesting that overall some $74.1 \%$ of the sample, ranging from $65.9 \%$ in Australia to $91.2 \%$ in the UK, did use other equipment in addition to lighting. While some of this equipment was basic such as timer units and oscillating fans, much of it was more sophisticated, including exhaust systems (32.5\%), extractor fans $(28.7 \%)$ and fan silencers/dampeners (13.8\%). Chemical fertilizers were significantly more likely to be used by respondents from the UK (61.0\%) and Australia (45.3\%) than they were among those from Denmark (34.6\%). The next section looks at factors associated with the use of these chemicals.

\subsubsection{Variables associated with use of chemical fertilizers, supplements and insecticides}

The data on variables associated with the use of chemical fertilizers, supplements and insecticides is presented in Table 4 in univariate form to examine the factors related to use of these chemicals in isolation, and then in Table 5 the result of the logistic regression analysis is presented which examines the unique contribution of these variables controlling for the effect of all the other predictor variables.

Table 4 shows that, as noted above, there were significant differences in the use of these chemicals between countries. Use was significantly higher among those who grew to sell, were male growers, grew using artificial lights (NS-AL and S-AL), had a grow area of 3 square meters or less, and who communicated with growers online who they did not meet face-toface. Those who used chemical fertilizers tended to be slightly older than those who did not. Growers who said that no-one else knew about their crop were less likely to use chemical 
fertilizers than those who reported that 1-5 others knew about their crop. Employment status, the number of people they grew their crop with and the number of plants they typically grew were not associated with the use of chemical fertilizers, supplements and insecticides.

The logistic regression analysis presented in Table 5 showed that when controlling for the effect of all these other variables, the only unique predictor of the use of chemicals was grow method. Specifically, respondents who said they grew in S-AL were at 2.86 greater odds of using chemical fertilizers than those who grew in S-NL, and those who grew using hydroponic and other sophisticated methods (NS-AL) were at 11.89 greater odds of using chemical fertilizers than those who grew in S-NL. None of the other predictors in the final model reached significance although a finding that approached significance $(p=0.053)$ was that those who communicated online with other growers were more likely to report use of chemicals.

\subsection{Discussion}

\subsection{Growing method and location}

Regarding growing practices, the finding that such high proportions of the sample grew in SAL, particularly among participants from Denmark and the UK, should be noted. Indeed, while much of the focus is on hydroponic growers, in each of the three countries those who grew using S-AL outnumbered NS-AL (hydroponic) growers roughly 2-4 fold. Furthermore, these S-AL growers were almost three times as likely as S-NL growers to use chemical fertilizers. Future research should investigate S-AL growers further. Again, the high proportions of use of artificial light in UK compared to the other countries should not be a surprise, yet it was interesting to see the rather extensive use of lighting and other equipment across the sample. This finding reflects the time and resources that many of these largely small-scale cannabis growers invest to produce their crop. 


\subsection{Use of chemicals}

With regards to the predictors of use of chemical fertilizers, supplements and insecticides, the finding that despite the univariate differences, this variance was largely a function of growing method (S-NL, vs S-AL and principally the use of hydroponic and other advanced cultivation techniques (NS-AL)), is consistent with solution-based non-soil growing systems requiring soluble chemical fertilizers. But none-the-less, it was interesting to see that even among those growers who used S-AL, the use of chemicals also was relatively high.

It is apparent from online posts (e.g. N3ro, 2017) and the difficulties some respondents in this study had in knowing whether the fertilizers, nutrients and pesticides were natural or chemical based, that there is much uncertainty about this issue among growers. There are a variety of factors that contribute to the difficulties in identifying products containing PGRs and other chemical components. In an environment where there is an absence of government regulation and no control over labelling, growers are left to rely on advice from grow-shops (who, as retailers of the same products, have a clear conflict of interest), advice from peers in the online cannabis community (where there clearly are conflicting opinions and ambiguity), or advice from other growers. Decorte (2011) has suggested that, even among experienced growers who see themselves as 'experts', this user 'lore' can be based on hearsay and urban myths. The lack of quality objective information about the content of products sold to cannabis growers in part reflects the lack of regulatory controls aimed at protecting the purchasers of these products and others who consume cannabis which they grow.

While cannabis growing for recreational use in these three countries is still illegal (although in Australia and the UK growing for medical purposes by a small number of companies is allowed), there is an interface between this illegal activity and aspects of regulated business which make profit from the sale of products targeted at, and used by, cannabis growers in the 
illicit market. There is no doubt that, from a consumer protection perspective, the regulation of these products and their constituents and labelling has been less rigorous than one might expect to see in aspects of the industry which supplies fertilizers and pest control products used in the (legal) food industry, or indeed the legal tobacco industry. It is without question that, while regulation of products which are manufactured and sold within countries has its challenges, regulating products manufactured in other countries and sold online around the world is even more problematic. Despite this, any read of the blog sites and online forums frequented by cannabis growers indicates that many are concerned about the chemicals that they put on their cannabis crops, but there is much uncertainty about the make-up and toxicity of various products and whether 'flushing' or a withholding period eliminates the presence of these chemicals in the final product. Indeed, making information available to this online peer community may prove a more effective, or additional, strategy than simply pursuing the government regulation route.

Finally, the results of this study support Decorte's (2010) previous observation that with the online dissemination of information about sophisticated growing techniques and equipment, the use of these techniques and equipment may not be a reliable indicator of the scale of the operation or a marker for involvement of organized criminal networks. We found that three in five of these largely small-scale growers in our sample used such techniques.

\subsection{Limitations}

The principal limitation of this study is that it is a non-representative sample, necessitating caution in generalizing from these results (Lenton et al., 2015). On the other hand, studies employing representative samples of the general population typically recruit only small numbers of cannabis growers (See Barratt and Lenton, 2015) and consequently our success in accessing 1,722 current/recent cannabis growers across three countries makes this study a 
useful contribution to the limited extant literature. The self-report nature of the data has its own limitations. This was evident in the participants' self-rating of fertilizers being 'non-chemical' when on several occasions, the brands mentioned had previously been identified as containing chemicals and indeed some known PGRs (e.g. Integral Hydroponics, 2015; Manic Botanix, undated; Sirius, 2016). A related limitation was our inability, due to lack of regulations regarding constituents and labelling, to clearly identify products containing PGRs which would likely have made for a more telling analysis, given recent concerns about the application of PGRs and their implications for health. We also acknowledge that as we were limited by the numbers of variables we could include due to the constraints of the web survey methodology, there may be errors of omission in the predictors of chemical use.

\subsection{Future research}

This study highlights the need for future research with cannabis growers to enquire about growing practices and the use of chemical fertilizers, nutrients and insecticides which have been shown to be a serious risk to health. However, further research should be done which attempts to purchase these products and analyze their chemical constituents to build on the work of cannabis activists that have challenged powerful and unscrupulous segments within the hydroponics industry to raise these concerns. Ideally this work can be done through collaboration between researchers, cannabis growers, toxicologists, consumer advocate organizations and more reputable members of the hydroponics industry. Whether in the legal or illegal market cannabis growers and users have a right to know what chemicals are in the products that are marketed to enhance their crops.

Clearly too, the uncertainty about the effectiveness of 'flushing' the crop and the apparent widespread use of this practice is an issue that could be the focus of future research. Asking cannabis growers about their use of flushing and their beliefs about it would be a good place to 
start. While we understand (Steven Carruthers, personal communication 23.03.17) that flushing does not remove PGRs, toxicological and biological studies employing post-harvest Gas Chromatography-Mass Spectrometry (GCMS) analysis of cannabis that was versus was not 'flushed' would potentially provide useful information which would be welcomed by cannabis growers. 


\section{Acknowledgements}

We would like to thank the thousands of cannabis cultivators who completed our questionnaire. Our research would not be possible without their efforts. Thanks also to all the people and organizations who supported and promoted our research, including but not limited to: Bluelight.org, Chris Bovey, Nimbin Hemp Embassy, NORML-UK, OZStoners.com, shamanaustralis.com, and all the coffee shops, grow shops and headshops that helped us. We would like to acknowledge the Nordic Centre for Welfare and Social Issues (NVC) and the Centre for Alcohol and Drug Research at Aarhus University for funding and hosting several our project meetings. Monica Barratt is supported by a fellowship from the NHMRC (APP1070140). The National Drug Research Institute at Curtin University and the National Drug and Alcohol Research Centre at the University of New South Wales are supported by funding from the Australian Government under the Drug and Alcohol Program. We also acknowledge the contribution of the Victorian Operational Infrastructure Support Program received by the Burnet Institute. Thanks to Arno Hazekamp and Steven Carruthers for their comments on an earlier draft of this paper. An earlier version of this paper was presented at the International Society for the Study of Drug Policy Conference in Aarhus, Denmark in 2017.

Conflict of interest: None of the authors have any known conflict of interest. 


\section{Tables}

Table 1. Demographic characteristics

\begin{tabular}{|c|c|c|c|c|c|c|}
\hline & Australia & Denmark & UK & Total & Sig $^{*}$ & $\begin{array}{l}\text { Cases in } \\
\text { Log Reg }\end{array}$ \\
\hline Gender \% & $(n=489)$ & $(n=809)$ & $(n=397)$ & $(n=1695)$ & & $(n=1190)$ \\
\hline Male & 87.5 & 91.6 & 94.7 & 91.1 & .001 & 90.6 \\
\hline Age in yrs & $(n=485)$ & $(\mathrm{n}=809)$ & $(n=381)$ & $(n=1675)$ & & $(n=1190)$ \\
\hline Median & 35 & 31 & 33 & 33 & & 34 \\
\hline Mean Age & 37.2 & 33.8 & 33.8 & 34.8 & .000 & 32 \\
\hline IQR & $27-47$ & $23-43$ & $25-41$ & $25-43$ & & $24-42$ \\
\hline Range & $18-71$ & $18-70$ & $18-63$ & $18-71$ & & $18-70$ \\
\hline Employment \% & $(n=488)$ & $(n=810)$ & $(n=398)$ & $(n=1696)$ & & $(n=1171)^{\star \star}$ \\
\hline Full-time work & 44.1 & 38.0 & 41.0 & 40.4 & .094 & 42.6 \\
\hline Part-time or casual work & 13.3 & 11.0 & 7.8 & 10.9 & .032 & 10.2 \\
\hline Self-employed & 17.2 & 9.1 & 17.1 & 13.3 & .000 & 12.8 \\
\hline Any employment (FT, PT or self) & 69.5 & 55.1 & 62.3 & 60.0 & .000 & 52.4 \\
\hline Full-time student & 9.0 & 23.1 & 9.5 & 15.9 & .000 & 16.6 \\
\hline Part-time student & 2.5 & 3.2 & 2.5 & 2.8 & .668 & 2.7 \\
\hline Unemployed - looking for work & 4.9 & 8.3 & 9.0 & 7.5 & .034 & 7.5 \\
\hline Benefits/pension & 6.8 & 3.2 & 10.1 & 5.8 & .000 & 4.8 \\
\hline Disability/Sickness benefits & 2.0 & 5.5 & 5.5 & 4.5 & .007 & 3.8 \\
\hline Home duties & 2.3 & 1.5 & 8.0 & 3.2 & .000 & 3.2 \\
\hline Retired & 3.9 & 8.4 & 1.3 & 5.4 & .000 & 4.8 \\
\hline Not seeking work & 9.0 & 2.7 & 1.3 & 4.2 & .000 & 4.2 \\
\hline Other & 0.0 & 0.2 & 0.0 & 0.1 & .335 & 0.2 \\
\hline Refused & 0.4 & 0.7 & 1.3 & 0.8 & .353 & 0.4 \\
\hline Living situation \% & $(n=488)$ & $(n=810)$ & $(n=398)$ & $(n=1696)$ & & $(n=1172)$ \\
\hline No-one, I live alone & 13.9 & 32.5 & 20.6 & 24.3 & .000 & 24.7 \\
\hline My (step)child/ren & 28.5 & 22.0 & 24.4 & 24.4 & .029 & 24.1 \\
\hline My friends & 4.3 & 5.3 & 4.8 & 4.9 & .716 & 4.9 \\
\hline My grandparents & 0.4 & 0.5 & 1.3 & 0.6 & .221 & 0.6 \\
\hline My housemates & 11.5 & 3.7 & 9.0 & 7.2 & .000 & 7.8 \\
\hline My (step)parents & 9.8 & 9.4 & 12.3 & 10.2 & .270 & 10.0 \\
\hline My spouse / partner / boy(girl)frienc & 59.0 & 42.0 & 47.2 & 48.1 & .000 & 48.4 \\
\hline My siblings or other family member: & 6.8 & 4.6 & 8.0 & 6.0 & .041 & 5.5 \\
\hline Homeless & 0.0 & 0.1 & 0.0 & 0.1 & .006 & 0.1 \\
\hline I don't want to answer & 2.7 & 1.6 & 4.8 & 2.7 & .006 & 1.9 \\
\hline Other & 0.2 & 0.2 & 0.0 & 0.2 & .622 & 0.3 \\
\hline
\end{tabular}

* Sig of comparisons between the 3 countries

** There were 19 missing cases 
Table 2. Growing practices

\begin{tabular}{|c|c|c|c|c|c|}
\hline & Australia & Denmark & UK & Total & Sig \\
\hline Grow method \%* & $(n=403)$ & $(n=730)$ & $(\mathrm{n}=350)$ & $(n=1483)$ & .000 \\
\hline Sunlight (only) \& soil ${ }^{* *}$ & 55.6 & 44.7 & 10.3 & 39.5 & \\
\hline Artificial light \& soil & 28.5 & 44.7 & 67.7 & 45.7 & \\
\hline Artificial light \& non-soil (Hydro) & 15.9 & 10.7 & 22.0 & 14.8 & \\
\hline Growing location \% ${ }^{\star \star \star}$ & $(\mathrm{n}=487)$ & $(n=805)$ & $(n=388)$ & $(n=1674)$ & \\
\hline In a garden & 51.5 & 49.4 & 11.3 & 41.3 & .000 \\
\hline Inside a cupboard & 17.2 & 31.9 & 36.1 & 28.6 & .000 \\
\hline $\begin{array}{l}\text { In a room that is also used for other } \\
\text { things }\end{array}$ & 11.9 & 25.0 & 22.2 & 20.5 & .000 \\
\hline In parks, bush, forests or fields & 16.8 & 22.7 & 8.0 & 17.6 & .000 \\
\hline In a greenhouse & 4.1 & 20.2 & 9.0 & 13.0 & .000 \\
\hline $\begin{array}{l}\text { In a special room just used for growing } \\
\text { (grow room) }\end{array}$ & 8.8 & 9.1 & 14.7 & 10.3 & .018 \\
\hline On a balcony & 4.9 & 17.3 & 2.3 & 10.2 & .000 \\
\hline Inside a shed & 15.0 & 7.7 & 8.8 & 10.1 & .000 \\
\hline In a basement & 2.7 & 6.7 & 7.0 & 5.6 & .005 \\
\hline $\begin{array}{l}\text { In a house / apartment that only used } \\
\text { for growing (grow house) }\end{array}$ & 0.4 & 1.0 & 1.5 & 1.0 & .256 \\
\hline In a warehouse & 0.2 & 1.2 & 0.8 & 0.8 & .132 \\
\hline Other & 7.4 & 8.3 & 11.1 & 8.7 & .257 \\
\hline I don't know & 0.0 & 0.4 & 0.3 & 0.2 & .408 \\
\hline I don't want to answer & 3.7 & 2.5 & 5.2 & 3.5 & .089 \\
\hline
\end{tabular}

${ }^{*} \mathrm{NB}$ : there were $5(0.3 \%)$ cases who stated that they used natural light in a non-soil medium. Because of the small $\mathrm{n}$ these were excluded here and coded as missing in this analysis.

** Some 238 respondents grew plants under both sunlight and artificial light (see footnote Table 3). This variable is coded to those that only grew under sunlight

${ }^{* * *}$ This was a multiple response item 
Table 3. Lighting, other equipment and fertilizers

\begin{tabular}{|c|c|c|c|c|c|}
\hline & Australia & Denmark & UK & Total & Sig \\
\hline Type of lighting $\%^{\star}$ & $(n=489)$ & $(n=811)$ & $(n=415)$ & $(\mathrm{n}=1715)$ & \\
\hline Sunlight** & 63.8 & 60.9 & 21.4 & 52.2 & .000 \\
\hline High pressure sodium lamp/s & 34.6 & 37.9 & 58.6 & 41.9 & .000 \\
\hline Fluorescent lamp/s & 18.2 & 14.1 & 30.4 & 19.1 & .000 \\
\hline Energy saving lamp/s & 8.0 & 18.7 & 18.1 & 15.5 & .000 \\
\hline Metal halide lamp/s & 13.1 & 8.4 & 20.0 & 12.5 & .000 \\
\hline Other & 8.0 & 12.0 & 14.2 & 11.4 & .010 \\
\hline I don't know & 6 & .2 & .5 & 4.1 & .582 \\
\hline I don't want to answer & .4 & .6 & .7 & 0.6 & .814 \\
\hline Other equipment used \%* & $(\mathrm{n}=472)$ & $(n=791)$ & $(n=411)$ & $(n=1674)$ & \\
\hline Timer unit & 45.8 & 48.5 & 72.5 & 53.6 & .000 \\
\hline Oscillating fan & 36.2 & 48.5 & 58.6 & 47.6 & .000 \\
\hline Light reflecting lining for the walls & 39.4 & 38.8 & 68.1 & 46.2 & .000 \\
\hline Growing substrates & 37.5 & 47.7 & 47.4 & 44.7 & .001 \\
\hline $\mathrm{PH}$ test kit & 43.4 & 33.1 & 58.4 & 42.2 & .000 \\
\hline Thermometer & 28.0 & 36.8 & 53.8 & 38.5 & .000 \\
\hline Carbon filter & 25.6 & 30.0 & 58.6 & 35.8 & .000 \\
\hline Inlet fan & 23.5 & 41.2 & 37.7 & 35.4 & .000 \\
\hline Exhaust system & 21.4 & 38.1 & 34.5 & 32.5 & .000 \\
\hline Extractor fan & 40.5 & 1.3 & 68.1 & 28.7 & .000 \\
\hline Water pump & 25.6 & 14.5 & 24.8 & 20.2 & .000 \\
\hline Air pump & 20.6 & 13.7 & 19.2 & 17.0 & .003 \\
\hline Fan silencer/dampener & 12.1 & 12.1 & 19.0 & 13.8 & .002 \\
\hline Water heater & 10.6 & 6.2 & 11.7 & 8.8 & .002 \\
\hline No other equipment/materials & 34.1 & 30.8 & 6.8 & 25.9 & .000 \\
\hline I don't want to answer & .4 & .9 & 1.0 & 0.8 & .580 \\
\hline Other equipment & 11.9 & 14.0 & 19.2 & 14.7 & .007 \\
\hline Use chemical fertilizers, supplements & $(n=475)$ & $(n=792)$ & $(n=392)$ & $(n=1659)$ & \\
\hline and insecticides $\%$ & 45.3 & 34.6 & 61.0 & 43.9 & .000 \\
\hline
\end{tabular}

${ }^{*} \mathrm{NB}$ these were multiple response items

${ }^{* *}$ As respondents could choose more than one option, proportions of people growing in sunlight appear larger than in Table 2 because some 238 people reported they grew their cannabis in both sunlight and artificial light, either because they had some plants under artificial light and some in sunlight or they moved plants from under lights (indoors) to sunlight (presumably by windows or outside). 
Table 4. Variables associated with use of chemical fertilizers, supplements and insecticides

\begin{tabular}{|c|c|c|c|c|}
\hline & $\begin{array}{c}\text { No } \\
\text { Chemicals }\end{array}$ & $\begin{array}{c}\text { Use } \\
\text { Chemicals }\end{array}$ & Total & Sig. \\
\hline Country \% & $(n=931)$ & $(n=728)$ & $(n=1659)$ & .000 \\
\hline Australia & 54.7 & 45.3 & 100.0 & \\
\hline Denmark & 65.4 & 34.6 & 100.0 & \\
\hline UK & 39.0 & 61.0 & 100.0 & \\
\hline Grow to Sell \% & $(n=929)$ & $(n=724)$ & $(n=1653)$ & .000 \\
\hline No & 58.0 & 42.0 & 100.0 & \\
\hline Yes & 33.9 & 66.1 & 100.0 & \\
\hline Gender \% & $(n=918)$ & $(n=714)$ & $(n=1632)$ & .000 \\
\hline Female & 73.4 & 26.6 & 100.0 & \\
\hline Male & 54.6 & 45.4 & 100.0 & \\
\hline Age (yrs) & $(n=906)$ & $(n=709)$ & $(n=1675)$ & \\
\hline Median & 33 & 32 & 33 & \\
\hline Mean Age & 35.6 & 33.9 & 34.8 & .005 \\
\hline IQR & $25-45$ & $25-41$ & $25-43$ & \\
\hline Range & $18-70$ & $18-71$ & $18-71$ & \\
\hline Employment \% & $(n=919)$ & $(n=714)$ & $(n=1633)$ & .010 \\
\hline Not employed & 60.3 & 39.7 & 100.0 & \\
\hline Employed incl. self employed & 53.8 & 46.2 & 100.0 & \\
\hline Grow method \% & $(\mathrm{n}=861)$ & $(n=572)$ & $(n=1433)$ & .000 \\
\hline Soil \& sunlight (S-NL) & 81.0 & 19.0 & 100.0 & \\
\hline Soil \& Artificial light (S-AL) & 54.4 & 45.6 & 100.0 & \\
\hline Non-soil \& Artificial light (NS-AL) & 20.6 & 79.4 & 100.0 & \\
\hline Growing area $\%$ & $(n=859)$ & $(n=685)$ & $(n=1544)$ & .000 \\
\hline Up to 3 square meters & 49.8 & 50.2 & 100.0 & \\
\hline Over 3 square meters & 61.4 & 38.6 & 100.0 & \\
\hline Number of plants typically grown \% & $(n=883)$ & $(n=695)$ & $(n=1578)$ & .756 \\
\hline Up to 6 plants & 56.5 & 43.5 & 100.0 & \\
\hline 7-10 plants & 55.9 & 44.1 & 100.0 & \\
\hline More than 10 plants & 56.0 & 44.0 & 100.0 & \\
\hline How many people grow crop with \% & $(n=922)$ & $(n=721)$ & $(n=1643)$ & .027 \\
\hline I grow alone & 53.9 & 46.1 & 100.0 & \\
\hline With 1 other & 59.0 & 41.0 & 100.0 & \\
\hline $2-3$ others & 66.7 & 33.3 & 100.0 & \\
\hline More than 3 others & 60.6 & 39.4 & 100.0 & \\
\hline How many people know about your crop \% & $(n=917)$ & $(n=718)$ & $(n=1635)$ & .000 \\
\hline None & 60.3 & 39.7 & 100.0 & \\
\hline 1 other person & 47.2 & 52.8 & 100.0 & \\
\hline $2-5$ others & 53.1 & 46.9 & 100.0 & \\
\hline $6-10$ others & 61.1 & 38.9 & 100.0 & \\
\hline More than 10 others & 63.5 & 36.5 & 100.0 & \\
\hline Communicate with other growers online & $(n=910)$ & $(n=715)$ & $(n=1625)$ & .000 \\
\hline No & 63.7 & 36.3 & 100.0 & \\
\hline Yes & 48.2 & 51.8 & 100.0 & \\
\hline
\end{tabular}


Table 5. Logistic regression predicting use of chemical fertilizers $(\mathrm{N}=1190)$

\begin{tabular}{|c|c|c|c|}
\hline Use of chemical fertilizers & OR & 95\%C.I. & Sig \\
\hline \multicolumn{4}{|l|}{ Country } \\
\hline Australia & 1.00 & & \\
\hline Denmark & 0.83 & $(0.61-1.13)$ & .231 \\
\hline UK & 1.45 & $(0.98-2.14)$ & .063 \\
\hline \multicolumn{4}{|l|}{ Grow to sell it } \\
\hline No & 1.00 & & \\
\hline Yes & 1.60 & $(0.95-2.70)$ & .078 \\
\hline \multicolumn{4}{|l|}{ Grow area in meters } \\
\hline Up to 3 square meters & 1.00 & & \\
\hline More than 3 square meters & 0.78 & $(0.60-1.02)$ & .070 \\
\hline \multicolumn{4}{|l|}{ Communicate with other growers online } \\
\hline No & 1.00 & & \\
\hline Yes & 1.31 & $(1.00-1.72)$ & .053 \\
\hline \multicolumn{4}{|l|}{ Grow method } \\
\hline Soil \& sunlight (S-NL) & 1.00 & & \\
\hline Soil \& Artificial light (S-AL) & 2.86 & $(2.08-3.94)$ & .000 \\
\hline Non-soil \& Artificial light (NS-AL) & 11.89 & $(7.64-18.52)$ & .000 \\
\hline
\end{tabular}




\section{References}

Barratt, M.J., Bouchard, M., Decorte, T., Vibeke Asmussen, F., Hakkarainen, P., Lenton, S., Malm, A., Nguyen, H., Potter, G.R., 2012. Understanding global patterns of domestic cannabis cultivation. Drugs and Alcohol Today 12(4), 213-221.

Barratt, M.J., Ferris, J.A., Lenton, S., 2015. Hidden populations, online purposive sampling, and external validity: Taking off the blindfold. Field Methods 27(1), 3-21.

Barratt, M.J., Lenton, S., 2015. Representativeness of online purposive sampling with Australian cannabis cultivators. International Journal of Drug Policy 26(3), 323-326.

Barratt, M.J., Potter, G.R., Wouters, M., Wilkins, C., Werse, B., Perälä, J., Pedersen, M.M., Nguyen, H., Malm, A., Lenton, S., Korf, D., Klein, A., Heyde, J., Hakkarainen, P., Frank, V.A., Decorte, T., Bouchard, M., Blok, T., 2015. Lessons from conducting trans-national Internet-mediated participatory research with hidden populations of cannabis cultivators. International Journal of Drug Policy 26(3), 238-249.

Decorte, T., 2010. Small scale domestic cannabis cultivation: An anonymous Web survey among 659 cannabis cultivators in Belgium. Contemporary Drug Problems 37(2), 341-370.

Decorte, T., 2011. "Stories", "facts" and "myths" - perceptions of domestic cultivators on potency and quality of cannabis, in: Decorte, T., Potter, G., Bouchard, M. (Eds.), World wide weed. Global Trends in Cannabis Cultivation and its Control. Ashgate, London, pp. 91-108.

Decorte, T., Barratt, M., Nguyen, H., Bouchard, M., Malm, A., Lenton, S., 2012. International Cannabis Cultivation Questionnaire (ICCQ) (Version 1.1). Global Cannabis Cultivation Research Consortium. Accessed at http://worldwideweed.nl/iccq/ (Accessed 2 February, 2018).

Decorte, T., Potter, G.R., 2015. The globalisation of cannabis cultivation: A growing challenge. International Journal of Drug Policy 26(3), 221-225.

Diclemente, C.C., Corno, C.M., Graydon, M.M., Wiprovnick, A.E., Knoblach, D.J., 2017. Motivational interviewing, enhancement, and brief interventions over the last decade: A review of reviews of efficacy and effectiveness. Psychology of Addictive Behaviors $31(8), 862-887$.

Gore, 2012. Plant Growth Regulators Poison Marijuana. Marijuana Growers HQ. Available at: http://marijuanagrowershq.com/plant-growth-regulators-poison-marijuana/ (Accessed 2 February, 2018). No archiving available.

Greenland, S., Finkle, W.D., 1995. A critical look at methods for handling missing covariates in epidemiologic regression analyses. American Journal of Epidemiology 142(12), 1255-1264.

Hakkarainen, P., Frank, V.A., Barratt, M.J., Dahl, H.V., Decorte, T., Karjalainen, K., Lenton, S., Potter, G., Werse, B., 2015. Growing medicine: Small-scale cannabis cultivation for medical purposes in six different countries. International Journal of Drug Policy 26(3), 250-256.

Haze, N., 2016. Flushing Cannabis Before Harvest (for Smoother Buds), Grow Weed Easy. Available at: http://www.growweedeasy.com/flushing (accessed 24 April, 2017) Archived by WebCite ${ }^{\circledR}$ at http://www.webcitation.org/6px8ojmK1 
Hazekamp, A., 2005. The quality of cannabis from the pharmacy is better: Comparison of price, dronabinol content and microbiological quality | Vergelijking van prijs, dronabinolgehalte en microbiologische kwaliteit: Cannabis uit de apotheek is beter. Pharmaceutisch Weekblad 140(12), 402-404.

Hazekamp, A., 2006. An evaluation of the quality of medicinal grade cannabis in the Netherlands. Cannabinoids 1(1), 1-9.

Hermes, K., 2011. Long-banned Alar (Daminozide) Shows Up on Hydroponic Store Shelves Before Being Removed Again. Americans For Safe Access, Available at: http://www.safeaccessnow.org/long_banned_alar_daminozide_shows_up_on_hydrop onic_store_shelves_before_being_removed_again (Accessed 2 February, 2018). Archived by WebCite ${ }^{\circledR}$ at http://www.webcitation.org/6wvAzNJhQ

How to grow marijuana.com, undated. Hydroponic Growing Systems, How to grow marijuana.com. Available at: http://howtogrowmarijuana.com/hydroponic-growingsystems/ (accessed 2 February, 2018). Archived by WebCite® at http://www.webcitation.org/6wvB7e0im

Integral Hydroponics, 2015. The Curious Case of the Flower Dragon. Available at: http://www.integralhydro.com/flower-dragon (Accessed 6 July, 2016). Archived by WebCite ${ }^{\circledR}$ at http://www.webcitation.org/6tI09rdw5

Kodiak, 2009. A complete guide to Topping, Training and Pruning, Available at: https://www.docdroid.net/yGaVKFC/complete-guide-to-topping-training-andpruning-by-kodiak.pdf.html\#page=3 (Accessed 21 April, 2017). Archived by WebCite ${ }^{\circledR}$ at http://www.webcitation.org/6tIOT2LQT

Lenton, S., Frank, V.A., Barratt, M.J., Dahl, H.V., Potter, G.R., 2015. Attitudes of cannabis growers to regulation of cannabis cultivation under a non-prohibition cannabis model. International Journal of Drug Policy 26(3), 257-266.

Manic Botanix, undated. PGRS and Medical Marijuana, Manic Botanix online grow mag. . Available at: https://manicbotanix.com/pgrs-and-medical-marijuana/ (Accessed 2 February, 2018). No archiving available.

Miller, M., Looi, S., 2017. Do you know enough about the risk of toxic pesticides in your weed?, Herb.co. Available at: http://herb.co/2017/03/04/toxic-pesticides-cannabis/ (Accessed 2 February, 2018). Archived by WebCite ${ }^{\circledR}$ at http://www.webcitation.org/6wvBUrDb5

N3ro, 2017. PGR'S what do you use?, Oz Stoners. Available at: https://cannabis.community.forums.ozstoners.com/topic/77167-pgrs-what-do-youuse/ (Accessed 24 April, 2017). Archived by WebCite ${ }^{\circledR}$ at http://www.webcitation.org/6tI1taENK

Potter, G., 2010. Weed, Need and Greed: A study of domestic cannabis cultivation. Free Association Books, London.

Potter, G.R., Barratt, M.J., Malm, A., Bouchard, M., Blok, T., Christensen, A.-S., Decorte, T., Frank, V.A., Hakkarainen, P., Klein, A., Lenton, S., Perälä, J., Werse, B., Wouters, M., 2015. Global patterns of domestic cannabis cultivation: Sample characteristics and patterns of growing across eleven countries. International Journal of Drug Policy 26(3), 226-237. 
Raber, J.C., Elzinga, S., Kaplan, C., 2015. Understanding dabs: Contamination concerns of cannabis concentrates and cannabinoid transfer during the act of dabbing. Journal of Toxicological Sciences 40(6), 797-803.

Robens, J.F., 1980. Carcinogenicity studies of selected herbicides. Vet. Hum. Toxicol. 22(5), 328-334.

Robertson, G., 2017. More than \$1 million of tainted medical marijuana destroyed, the Globe and Mail. Available at:

http://www.theglobeandmail.com/news/national/morethan1millionoftaintedmedicalm arijuanadestroyed/article34026223/ (Accessed 2 February, 2018). No archiving available.

Sirius, J., 2016. What are PGR'S and why are they in my weed?, High Times. Available at: http://hightimes.com/grow/what-are-pgrs-and-why-are-they-in-my-weed/ (Accessed 22 June, 2016). Archived by WebCite ${ }^{\circledR}$ att http://www.webcitation.org/6iSayqwwH

Subritzky, T., Pettigrew, S., Lenton, S., 2017. Into the void: Regulating pesticide use in Colorado's commercial cannabis markets. International Journal of Drug Policy 42, 86-96.

Sullivan, N., Elzinga, S., Raber, J.C., 2013. Determination of pesticide residues in cannabis smoke. Journal of Toxicology 2013. doi: 10.1155/2013/378168

Venhuis, B.J., van de Nobelen, S., 2015. Cannabis contaminants. Rijksinstituut voor Volksgezondheid en Milieu, Bilthoven. 


\section{Appendix 1: Brands of chemicals mentioned by respondents in open text field}

\begin{tabular}{|c|c|}
\hline Frequency & Brand name \\
\hline 100 & $\begin{array}{l}\text { Canna range: Canna Start, Canna Terra, Canna Aqua, Cannazym, Cannaboost, } \\
\text { Canna PK 13/14, Canna Rhizotonic, Canna Substra, Biocanna, Canna Coco }\end{array}$ \\
\hline 71 & $\begin{array}{l}\text { Biobizz: Topmax, Root juice, fertilizers (fish mix, biobloom, biogrow), organic } \\
\text { substrates (cocomix, light mix, all mix) }\end{array}$ \\
\hline 18 & General Hydroponics flora series Microbloom, Koolbloom, 3 part series Biosevia, \\
\hline 16 & $\begin{array}{l}\text { Ionic (by Growth Technology): Hydro, Hydro Hard Water, Coco, Soil, Starter } \\
\text { Packs, Cal-Mag Pro, PK Boost, UV Balance }\end{array}$ \\
\hline 16 & $\begin{array}{l}\text { Nutrifield Coco A \& B, NF Fulife, NF Zyme, NF Cargo Boost, Grow A \& B, } \\
\text { Bloom A \& B, Bud A \& B }\end{array}$ \\
\hline 15 & $\begin{array}{l}\text { Advanced Nutrients: Voodoo Juice, B-52, Piranha, Tarantula, Bud candy, Nirvana, } \\
\text { Bud Factor X, ph Perfect Sensi Bloom A \& B, ph Perfect Sensi Grow A \& B }\end{array}$ \\
\hline 12 & Miracle grow \\
\hline 12 & Superthrive \\
\hline 11 & Atami: B'cuzz Soil Nutrition A \& B, B'cuzz Hydro Nutrition A \& B \\
\hline 11 & Dutch Master: Advance and Gold Nutrients, Zone \\
\hline 10 & Neem oil \\
\hline 10 & Plant magic Oldtimer grow and bloom \\
\hline 9 & House \&Garden BudXL, H\&G Topbooster, H\&G Shooting powder, Coco specific \\
\hline 9 & Ozgrow Monsta bud, Monsta bloom \\
\hline 9 & Vitalink \\
\hline 6 & Big Bud \\
\hline 4 & Babybio \\
\hline 4 & Bionova \\
\hline 4 & Green Dream: A \& B \\
\hline 4 & Liquid Lead \\
\hline 4 & Seasol \\
\hline 3 & Canadian Express \\
\hline 3 & Dutch Pro Explode and root juice \\
\hline 3 & Dutchfest \\
\hline 3 & Humbolt County Range, Fox Farm \\
\hline 3 & Plagron \\
\hline 3 & Westland \\
\hline 3 & Yates thrive \\
\hline 2 & Bio grow \\
\hline 2 & Bloom bastic \\
\hline 2 & Chempak \\
\hline 2 & Gold label \\
\hline 2 & Green Haze grow \& Bloom \\
\hline 2 & Halo \\
\hline 2 & Hammerhead \\
\hline 2 & Headon \\
\hline 2 & Iguana juice \\
\hline 2 & Monster Bud \\
\hline 2 & Ozi Tonic \\
\hline 2 & Psycho (cyco) grow; Platinum \\
\hline
\end{tabular}




\begin{tabular}{|l|l|}
\hline 2 & Substral \\
\hline 1 & A Aptus start booster, Aptus Regulator, Aptus Break Out, \\
\hline 1 & Ace of Buds \\
\hline 1 & Alga Grow and bloom \\
\hline 1 & Amsterdam Indoors Grow \& Bloom \\
\hline 1 & Anti Spider Mites \\
\hline 1 & Aptus Range \\
\hline 1 & B Buddha Tree $9 / 18$ and Buddha Tree Meta Boost \\
\hline 1 & BAC base food, superbud, bloom stimulator \\
\hline 1 & Bio Heaven \\
\hline 1 & Biomix \\
\hline 1 & Blue Planet nutrients \\
\hline 1 & Bug clear ultra \\
\hline 1 & Carbo load, Carbo max \\
\hline 1 & Crop Shiva \\
\hline 1 & Dr Shimmel Terminator or Trounce \\
\hline 1 & Dutchgrow \\
\hline 1 & Eco-neem \\
\hline 1 & Enormous \\
\hline 1 & Flairform nutes \\
\hline 1 & Floriform \\
\hline 1 & Formlex \\
\hline 1 & Future Harvest Development \\
\hline 1 & GoGo Juice \\
\hline 1 & Grow more \\
\hline 1 & GT coco, Psychoo, The Resinator \\
\hline 1 & Happy frog \\
\hline 1 & Heavies powder \\
\hline 1 & Heavy weight PK 13-15 \\
\hline 1 & HESI \\
\hline 1 & Holland Secret Hydro \\
\hline 1 & Hulk \\
\hline 1 & Ivermectin \\
\hline 1 & King of Buds \\
\hline 1 & Liquid silicone \\
\hline 1 & Manutech Hydroponic A \& B \\
\hline 1 & Maxicrop \\
\hline 1 & Meteop Nutrients \\
\hline 1 & Nitrozyme \\
\hline 1 & Phostrogen \\
\hline 1 & QuickTurn \\
\hline 1 & Supio \\
\hline 1 & Supreme Nutrients \\
\hline & Zyme Alive \\
\hline
\end{tabular}


